Article

\title{
Experimental Investigation on the Effects of Ethanol-Enhanced Steam Injection Remediation in Nitrobenzene-Contaminated Heterogeneous Aquifers
}

\author{
Ruxue Liu ${ }^{1,2,3}$, Xinru Yang ${ }^{1,2,3}$, Jiayin Xie ${ }^{1,2,3}$, Xiaoyu Li ${ }^{1,2,3}$ and Yongsheng Zhao ${ }^{1,2,3, *}$ \\ 1 Key Laboratory of Groundwater Resources and Environment of Ministry of Education, College of New \\ Energy and Environment, Jilin University, Changchun 130021, China; liurx18@mails.jlu.edu.cn (R.L.); \\ xryang19@mails.jlu.edu.cn (X.Y.); xiejy20@mails.jlu.edu.cn (J.X.); xyl21@mails.jlu.edu.cn (X.L.) \\ 2 Jilin Provincial Key Laboratory of Water Resources and Environment, Jilin University, \\ Changchun 130021, China \\ 3 National and Local Joint Engineering Laboratory for Petrochemical Contaminated Site Control and \\ Remediation Technology, Jilin University, Changchun 130021, China \\ * Correspondence: zhaoyongsheng@jlu.edu.cn
}

check for updates

Citation: Liu, R.; Yang, X.; Xie, J.; Li, X.; Zhao, Y. Experimental Investigation on the Effects of Ethanol-Enhanced Steam Injection Remediation in NitrobenzeneContaminated Heterogeneous Aquifers. Appl. Sci. 2021, 11, 12029. https://doi.org/10.3390/ app112412029

Academic Editor: Bing Bai

Received: 1 November 2021

Accepted: 24 November 2021

Published: 17 December 2021

Publisher's Note: MDPI stays neutral with regard to jurisdictional claims in published maps and institutional affiliations.

Copyright: (c) 2021 by the authors. Licensee MDPI, Basel, Switzerland. This article is an open access article distributed under the terms and conditions of the Creative Commons Attribution (CC BY) license (https:/ / creativecommons.org/licenses/by/ $4.0 /)$.

\begin{abstract}
Steam injection is an effective technique for the remediation of aquifers polluted with volatile organic compounds. However, the application of steam injection technology requires a judicious selection of stratum media because the remediation effect of hot steam in heterogeneous layers with low permeability is not suitable. In this study, the removal effect of nitrobenzene in an aquifer was investigated through a series of two-dimensional sandbox experiments with different stratigraphic structures. Four types of alcohols were used during steam injection remediation to enhance the removal effect of nitrobenzene (NB)-contaminated heterogeneous aquifers. The principle of the removal mechanism of alcohol-enhanced organic compounds is that alcohols can reduce the surface tension of the contaminated water, resulting in Marangoni convection, thereby enhancing mass and heat transfer. The addition of alcohol may also reduce the azeotropic temperature of the system and enhance the volatility of organic compounds. The study revealed that all four alcohol types could reduce the surface tension from $72 \mathrm{mN} / \mathrm{m}$ to $<30 \mathrm{mN} / \mathrm{m}$. However, among these, only ethanol reduced the azeotropic temperature of $\mathrm{NB}$ by $15^{\circ} \mathrm{C}$, thereby reducing energy consumption and remediation costs. Therefore, ethanol was selected as an enhancing agent to reduce both surface tension and azeotropic temperature during steam injection. In the 2-D simulation tank, the interface between the low-and high-permeability strata in the layered heterogeneous aquifer had a blocking effect on steam transportation, which in turn caused a poor remediation effect in the upper low-permeability stratum. In the lens heterogeneous aquifer, steam flows around the lens, thereby weakening the remediation effect. After adding ethanol to the low-permeability zone, Marangoni convection was enhanced, which further enhanced the mass and heat transfer. In the layered and lens heterogeneous aquifers, the area affected by steam increased by $13 \%$ and $14 \%$, respectively. Moreover, the average concentration of NB was reduced by $51 \%$ in layered heterogeneous aquifers and by $58 \%$ in low-permeability lenses by ethanol addition. These findings enhance the remediation effect of steam injection in heterogeneous porous media and contribute to improve the remediation efficiency of heterogeneous aquifers by steam injection.
\end{abstract}

Keywords: steam injection; ethanol; azeotropic temperature; heterogeneous aquifers; nitrobenzene

\section{Introduction}

Steam injection is an important remediation technology that can effectively remove organic pollutants during site remediation [1-3]. In particular, steam injection technology can remediate contaminated sites containing multiple volatile or semi-volatile organic pollutants [4]. The remediation efficiency of steam injection technology primarily depends 
on the permeability of the stratum medium $[2,5,6]$. The volatility of organic compounds in water is closely related to temperature [7-10]. However, the transmission of steam may be limited by the soil particle size, resulting in a reduction in remediation efficiency [11,12]. In general, the remediation efficiency is the highest in homogeneous sand because of the large particle size and non-layered nature of the soil. Many researchers have used homogeneous sand to analyze the characteristics of steam injection $[4,13,14]$. However, a heterogeneous stratum structure is quite common at actual remediation sites [15,16]; thus, the impact of heterogeneous strata on the remediation effect should be considered.

Some studies have shown that the heterogeneity of the stratum can lead to unsatisfactory remediation effects [2]. Even in sandy soils, the heterogeneity of soil also affects the remediation effect. At present, systematic research on the migration, distribution, and remediation effects of steam in heterogeneous aquifers is lacking. In addition, only a few studies exist on the enhanced steam remediation of heterogeneous aquifers.

In the present study, a combination of thermal technologies such as steam injection with thermal conduction heating $(\mathrm{TCH})$ [17] or steam injection with electrical resistance heating $(\mathrm{ERH})$ was adopted to improve the remediation efficiency of steam injection in heterogeneous layers [18], with the aim of using steam injection in high-permeability zones and TCH or ERH in low-permeability zones. However, these methods are more expensive and complicated. Therefore, a method for strengthening steam injection to repair heterogeneous aquifers is needed.

Chao et al. proposed the addition of alcohol in the repair process of air sparging (AS) to enhance remediation efficiency [19]. N-pentanol and n-heptanol were selected as strengthening reagents as both could enhance the removal efficiency of organic compounds; however, the effect of $\mathrm{n}$-heptanol was stronger than that of $\mathrm{n}$-pentanol. The key mechanism is that alcohol molecules can interact with organic compounds at the interface, resulting in increased organic compound volatilization. Based on the theory of enhanced volatilization, it is assumed that alcohols can enhance volatilization more than surfactants $[19,20]$. Volatility is also a key factor in the process of steam injection and remediation of organic pollutants, which also determines the increased volatilization of organic compounds [21]. According to some studies, alcohol can be used as a surfactant to reduce the surface tension of the solution $[22,23]$ and thus can be used to enhance the volatilization of organic compounds. Previous studies have shown that the addition of ethanol, n-propanol, and n-butanol can reduce surface tension and enhance mass transfer [24]. This study aimed to explore the effects of these alcohols on organic compounds as strengthening reagents.

During steam injection remediation, the removal rate of organic compounds increases with an increase in temperature, and the remediation efficiency increases significantly at boiling point $[8,25,26]$. Some organics can form azeotropes with water at temperatures lower than their boiling point $[27,28]$. Therefore, a lower azeotropic temperature can quickly remove organic matter. As alcohol and water can form azeotropes, this study investigated which alcohol could better reduce the azeotropic temperature of organic compounds using the common semi-volatile organic compound nitrobenzene (NB) in contaminated sites as the target pollutant.

Alcohol-enhanced steam injection has rarely been studied, therefore, this study investigated the effects of alcohol on the remediation of heterogeneous aquifers. The effects of the four alcohols (ethanol, n-butanol, n-pentanol, and n-heptanol) on the surface tension and azeotropic temperature of NB were studied. Heterogeneous layers with different permeability ratios $(R)$ were selected to compare the temperature distribution and removal efficiency of organic pollutants under different permeability ratios. The migration and distribution mechanisms of steam in a lens heterogeneous aquifer were also studied. In addition, the effect of alcohol-enhanced remediation was studied for a stratum with a weak remediation effect. This study aims to select an alcohol to enhance the effect of steam injection to remediate contaminated heterogeneous aquifers, thus extending the application of steam injection technology. 


\section{Theoretical Background}

\subsection{Marangoni Effect}

In a gas-liquid mass transfer process, the interface condition is important. Interfacial tension, molecular structure of the interface, intermolecular forces of combining gas and liquid molecules, and interface turbulence all have an important impact on the gas-liquid mass transfer process [29]. During gas-liquid mass transfer, the interfacial convection phenomenon is caused by the change in some physical properties of the liquid such as surface tension and density due to the mass transfer at the interface, which may lead to convective movement of the interfacial fluid [29-31]. Researchers attribute this to the Marangoni effect or Rayleigh effect caused by transmission, which in turn strengthens the transmission process [30,32]. During interphase mass transfer, when the temperature or concentration in different areas on the surface are different, a surface tension gradient is generated, resulting in the movement of liquid on the surface layer and liquid under the interface. This interfacial convection phenomenon is known as the Marangoni effect. The Marangoni effect not only has various geometric patterns on the flow structure, but also enhances the heat and mass transfer processes. Marangoni convection can be characterized by the dimensionless number $\mathrm{Ma}$, which is expressed as follows:

$$
\mathrm{Ma}=\frac{\mathrm{d} \Delta \sigma}{\mathrm{D} \mu}
$$

where $\mathrm{d}$ is the characteristic length $(\mathrm{m}) ; \Delta \sigma$ is the difference in surface tension between the surface fluid and the main fluid $\left(\mathrm{N} \mathrm{m}^{-1}\right)$; $\mathrm{D}$ is the diffusion coefficient of the solute in the fluid $\left(\mathrm{m}^{2} \mathrm{~s}^{-1}\right)$; and $\mu$ is the viscosity of the fluid (Pa s). In Equation (1), when $\mathrm{Ma}>0$ and exceeds a certain critical value, the surface tension gradient generated by the interface will cause Marangoni convection. In gas-liquid and liquid-liquid liquefaction processes, due to the changes in the physical and chemical properties of the system [33,34], the heat and mass transfer processes cause interfacial instability, and the surface tension is a function of concentration and temperature, which causes the temperature and concentration gradient of the interface to lead to the surface tension gradient of the interface, resulting in Marangoni convection.

\subsection{Alcohol-and Heat-Enhanced Marangoni Convection}

As the temperature change along the interphase surface can promote the surface tension gradient, it will also cause the Marangoni convection $[35,36]$. After heating, the surface tension decreases and the surface tension gradient increases, thereby enhancing the Marangoni convection and strengthening the mass transfer process [37,38]. The addition of alcohol reduces the surface tension, and with the evaporation of alcohol, the concentration of alcohol on the liquid film decreases, promoting the diffusion of alcohol molecules to the liquid film and enhancing the gradient of surface tension. This enhances the Marangoni convection $[39,40]$. The existence of interfacial convection can greatly enhance the interphase mass transfer process and reduce energy consumption.

\section{Materials and Methods}

\subsection{Materials}

Analytically pure (AR)-grade NB was obtained from Sinopharm Chemical Reagent Co. Ltd., and the alcohols used in this study are shown in Table 1. All the materials were used without further purification, and all aqueous solutions were prepared with deionized water.

\subsection{Experimental Methods \\ 3.2.1. Surface Tension}

Because ethanol and water are miscible, the surface tension at different volume fractions of ethanol was measured using a surface tension meter. Different volumes of ethanol 
and water were added to $40 \mathrm{~mL}$ headspace bottles and mixed well. The surface tension of the mixtures was measured at room temperature $\left(20^{\circ} \mathrm{C}\right)$. Reagents were added as shown in Table 2.

Table 1. List of alcohols used in this study.

\begin{tabular}{ccc}
\hline Alcohols & Purity & Manufacturer \\
\hline Ethanol & & Tianjin Huihang Chemical Technology Co. Ltd. \\
N-butanol & & Guangdong Guanghua Technology Co. Ltd. \\
N-pentanol & BR & Beijing Chemical Plant Co. Ltd. \\
N-heptanol & & Beijing Chemical Plant Co. Ltd. \\
\hline
\end{tabular}

Table 2. Specific plan of reagent addition.

\begin{tabular}{cccc}
\hline Ethanol: Water & Ethanol Volume Fraction & Ethanol $(\mathbf{m L})$ & Water $(\mathbf{m L})$ \\
\hline 1 & 1 & 40 & - \\
$9: 1$ & 0.9 & 36 & 4 \\
$8: 2$ & 0.8 & 32 & 12 \\
$7: 3$ & 0.7 & 28 & 16 \\
$6: 4$ & 0.6 & 24 & 20 \\
$5: 5$ & 0.5 & 20 & 24 \\
$4: 6$ & 0.4 & 16 & 28 \\
$3: 7$ & 0.3 & 12 & 32 \\
$2: 8$ & 0.2 & 8 & 36 \\
$1: 9$ & 0.1 & 4 & 40 \\
0 & 0 & - & \\
\hline
\end{tabular}

A total of $3 \times 32 \mathrm{~mL}$ of ultrapure water was added into three $40 \mathrm{~mL}$ headspace bottles separately, followed by $8 \mathrm{~mL}$ of n-butanol, n-amyl alcohol, and n-heptanol. The samples were placed in a shaker for $24 \mathrm{~h}$, and the speed of the shaker was set at $180 \mathrm{rpm} / \mathrm{min}$. The headspace bottles were left to stand for $30 \mathrm{~min}$, and then samples were extracted with $5 \mathrm{~mL}$ syringes to measure the surface tension by using a surface tension meter. Each experiment was performed in triplicate to avoid experimental errors.

\subsubsection{Effect of Alcohol on Azeotropy}

An azeotropic experimental device is shown in Figure 1. The azeotropic experiment primarily included the binary mixed system and ternary mixed system. The specific experimental scheme is presented in Table 3. The ratio of organic compound/water/alcohol was determined based on the optimal ratio of organic compound/water and the optimal ratio of water/alcohol obtained from previous studies on azeotropes of binary systems. The temperature measurement probes were placed in the upper, middle, and lower positions of the solution; subsequently, a condensate pipe was connected, and the solution was heated to $140{ }^{\circ} \mathrm{C}$ in an oil bath. The temperature reading was recorded every minute. Each experimental group was repeated thrice to avoid experimental errors.

\subsubsection{Steam Remediation of Nitrobenzene-Contaminated Heterogeneous Aquifer}

This part of the experiment was conducted in a 2-D simulation tank with the dimensions of $60 \mathrm{~cm}$ (length) $\times 50 \mathrm{~cm}$ (height) $\times 4 \mathrm{~cm}$ (width) (Figure 2). The steam injection well installed at the bottom of the tank for stem injection comprised a cylinder with a diameter of $4 \mathrm{~cm}$ and height of $7.5 \mathrm{~cm}$, having many tiny pores at the top. The tiny pores were covered with gauze to prevent sand from entering the steam injection well. There were 24 sampling ports in front of the tank to monitor the temperature using a multi-channel temperature detector (Shenzhen Hua Xin Measuring Instrument Company, Shenzhen, China). Figure 2a,b illustrates the experimental schematic design and the layered heterogeneous aquifer device, and Figure $2 \mathrm{c}$ shows the lens heterogeneous aquifer. The physical properties of the quartz sand samples used in the tests are presented in Table 4 . The 
experimental filling medium of the layered heterogeneous aquifer is presented in Table 5 . The purpose of the experimental design was to simulate the influence of the interface on steam migration when the upper layer was a low-permeability medium and the lower layer was a high-permeability medium in the actual site. The $\mathrm{R}$ values of the two groups differed by an order of magnitude, which depicts the scenario of stratified heterogeneous aquifers.

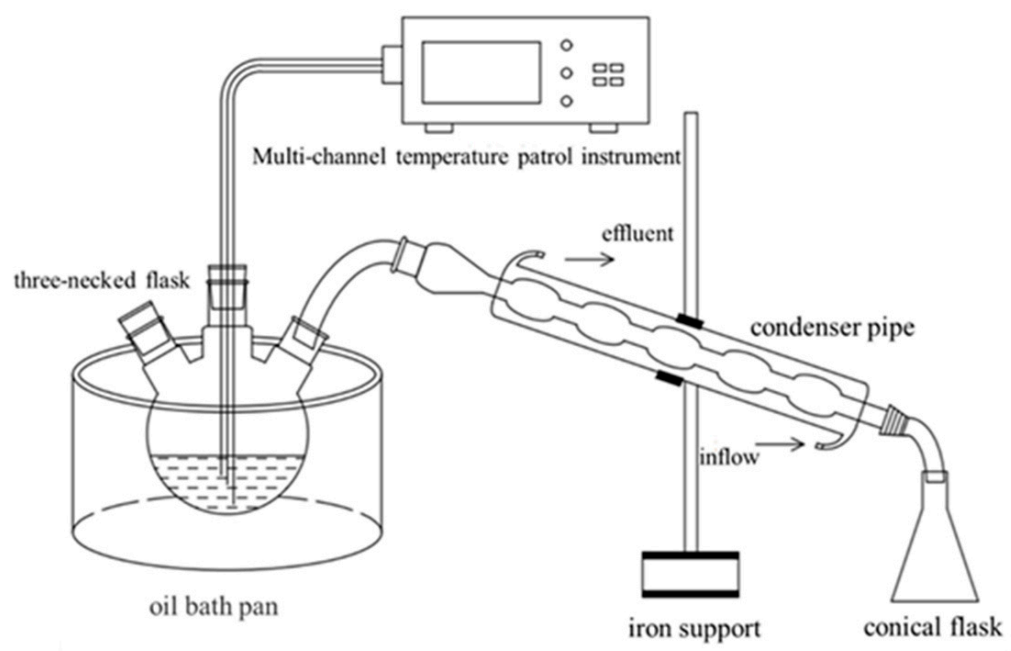

Figure 1. Schematic of the azeotropic test device.

Table 3. Specific scheme of the experiment.

\begin{tabular}{ccc}
\hline Test No. & Reagent Composition & Reagent Addition \\
\hline 1 & water + NB & $100 \mathrm{~mL}+30 \mathrm{~mL}$ \\
2 & water + NB + ethyl alcohol & $25 \mathrm{~mL}+30 \mathrm{~mL}+100 \mathrm{~mL}$ \\
3 & water + NB + n-butyl alcohol & $40 \mathrm{~mL}+30 \mathrm{~mL}+80 \mathrm{~mL}$ \\
4 & water + NB + n-amyl alcohol & $60 \mathrm{~mL}+30 \mathrm{~mL}+60 \mathrm{~mL}$ \\
5 & water + NB + n-heptanol & $90 \mathrm{~mL}+30 \mathrm{~mL}+30 \mathrm{~mL}$ \\
\hline
\end{tabular}
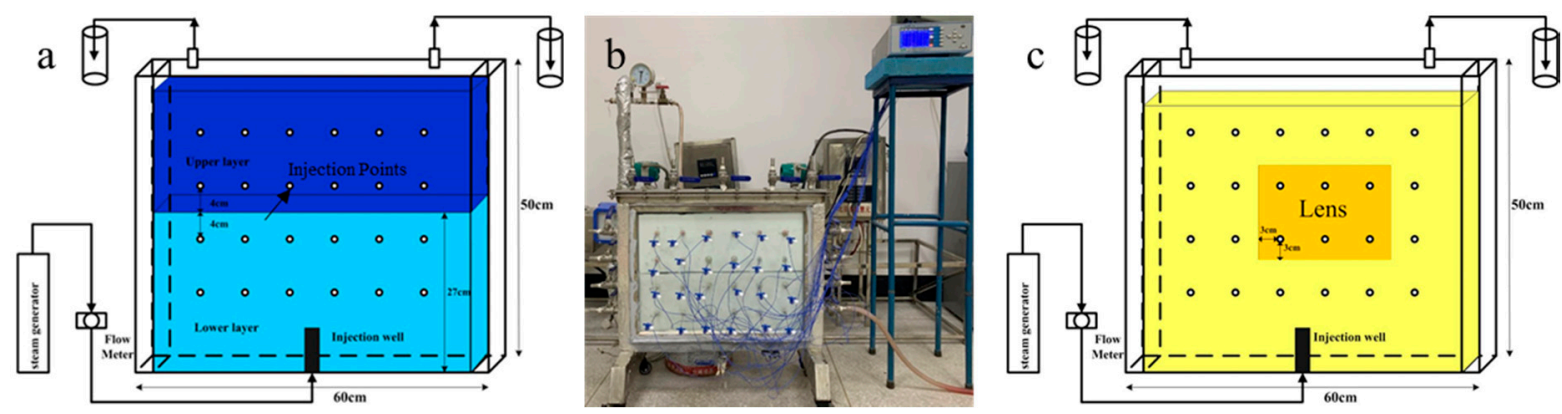

Figure 2. Schematic (a) and photo (b) of the experimental setup for the layered heterogeneous aquifer, and schematic of the experimental device for the lens heterogeneous aquifer (c).

Table 4. Properties of quartz sand samples in the tests.

\begin{tabular}{ccc}
\hline Soil Type & Particle Size $(\mathbf{m m})$ & Hydraulic Conductivity K (cm/s) \\
\hline Gravel & $3-5$ & $6.1 \times 10^{-1}$ \\
Coarse sand & $0.4-0.85$ & $6.5 \times 10^{-2}$ \\
Medium sand & $0.2-0.4$ & $3.5 \times 10^{-2}$ \\
Fine sand & $0.1-0.2$ & $1.6 \times 10^{-3}$ \\
\hline
\end{tabular}


Table 5. Specific experimental plan for the layered heterogeneous aquifer experiment.

\begin{tabular}{|c|c|c|c|}
\hline Test No. & Packing Configuration & & $\mathbf{R}$ \\
\hline 1 & $\begin{array}{l}\text { Upper layer } \\
\text { Lower layer }\end{array}$ & $\begin{array}{l}\text { Medium sand } \\
\text { Gravel }\end{array}$ & 17.4 \\
\hline 2 & $\begin{array}{l}\text { Upper layer } \\
\text { Lower layer }\end{array}$ & $\begin{array}{c}\text { Fine sand } \\
\text { Gravel }\end{array}$ & 381 \\
\hline
\end{tabular}

The background medium of the lens heterogeneous aquifer was filled with coarse sand and the lens was filled with fine sand. Before the experiment, tap water was continuously injected at a rate of $0.5 \mathrm{~m} \mathrm{~d}^{-1}$ by a peristaltic pump to ensure uniformity of the porous media and to remove entrapped air. Subsequently, $300 \mathrm{mg} / \mathrm{L} \mathrm{NB}$ was injected into the lower left water inlet until the concentration detected at the upper right water outlet was the same as the water inlet, which simulated the formation and stabilization of the NB contaminant plume. Steam was generated at a constant rate by a $3 \mathrm{~kW}$ steam generator (Norbest Machinery Manufacturing Co. Ltd., Wuhan, China), which was supplied by a constant flux of water producing saturated steam at a temperature of $120^{\circ} \mathrm{C}$ and pressure of $200 \mathrm{kPa}$. The steam flow was set to $1 \mathrm{~kg} \mathrm{~h}^{-1}$. The temperatures were continuously measured in the sandbox. Water samples were collected at selected intervals (0-270 min) using a disposable syringe. The concentration of $\mathrm{NB}$ in water was analyzed using liquid chromatography (HPLC, Agilent 1260, Santa Clara, CA, USA). The hydraulic conductivity ratio $\mathrm{R}$ is defined in the layered heterogeneous aquifer as follows:

$$
\mathrm{R}=\mathrm{K}_{\mathrm{l}} / \mathrm{K}_{\mathrm{u}}
$$

where $\mathrm{K}_{1}$ is the hydraulic conductivity of the lower layer medium and $\mathrm{K}_{\mathrm{u}}$ is the hydraulic conductivity of the upper layer medium.

\subsubsection{Ethanol-Enhanced Steam Remediation of Nitrobenzene-Contaminated Layered Heterogeneous Aquifers}

The experimental device shown in Figure 2 was the same as the previous experimental device. An experimental setting with a hydraulic conductivity ratio $R$ of 381 in the layered heterogeneous aquifer remediation experiment was selected to accelerate the remediation rate experiment. On the completion of the experiment, samples were analyzed for the distribution of pollutants in the aquifer. Furthermore, $500 \mathrm{~mL}$ of ethanol at a flow rate of $5 \mathrm{~mL} / \mathrm{min}$ with a peristaltic pump was injected above the interface to enhance the repair efficiency of the interface in the upper low-permeability zone. The injection positions are shown in Figure 2. In the lens heterogeneous aquifer, $300 \mathrm{~mL}$ ethanol was injected into the lens. The ethanol injection volume was calculated using Equation (3). Ethanol distribution stabilization for $2 \mathrm{~h}$ was conducted after injecting the ethanol. Later, the concentration distribution of the pollutants before remediation was analyzed. The concentration of NB was determined using liquid chromatography. After injecting hot steam, the sandbox temperature was continuously measured. Water samples were collected at 0-270 minintervals using a disposable syringe. Ethanol injection volume was calculated using the equation:

$$
\mathrm{V}=\mathrm{A} \times \mathrm{D} \times \sigma \times 0.3
$$

where $\mathrm{A}$ is the affected area of the low-permeability $\left(\mathrm{cm}^{2}\right)$; D is the thickness of the simulated tank $(\mathrm{cm}) ; \sigma$ is the porosity of the medium; and 0.3 is the volume fraction of ethanol.

\section{Results and Discussion}

\subsection{Effect of Alcohol on Surface Tension}

After adding different volumes of ethanol, the surface tension of the mixture system gradually decreased, with surface tension values of $72.6 \mathrm{mN} / \mathrm{m}, 22.3 \mathrm{mN} / \mathrm{m}$, and $30 \mathrm{mN} / \mathrm{m}$ 
at 0,1 , and 0.3 volume fractions of ethanol, respectively (Figure 3 ). Thus, when the volume of ethanol was $>0.3 \mathrm{~mL}$, the surface tension of the system significantly reduced, indicating that ethanol can reduce the surface tension of the solution and thus can be used as a surfactant. The optimal ratio of ethanol was 0.3 .

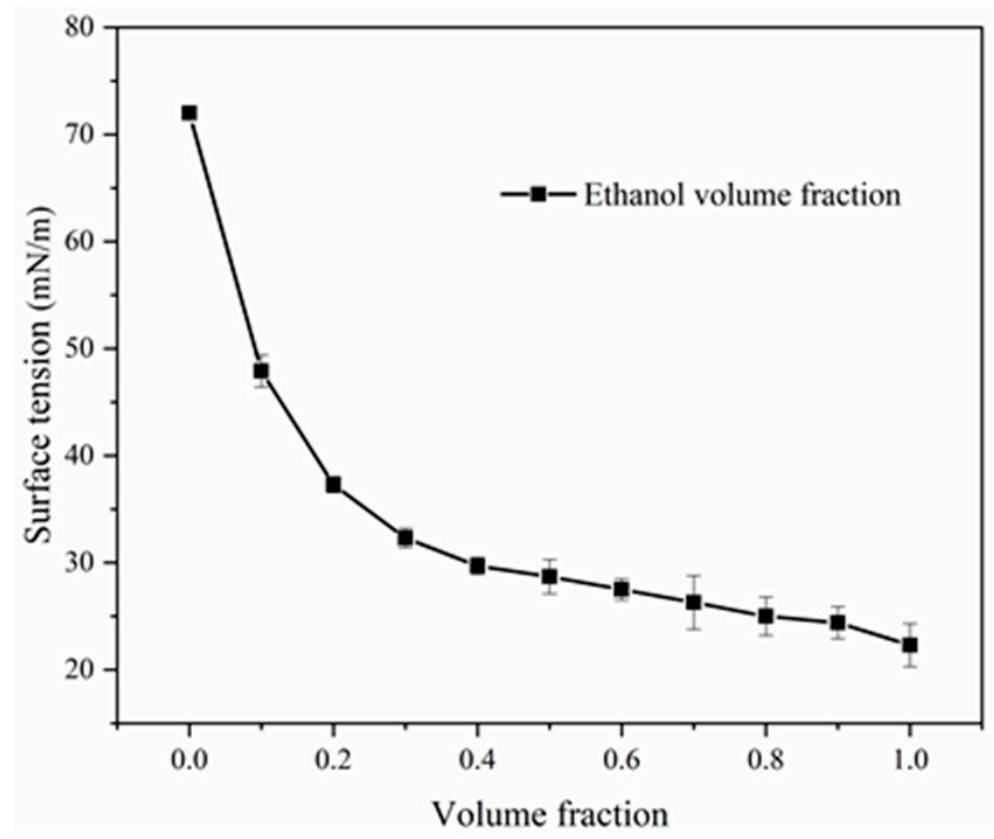

Figure 3. Change curve of surface tension under different ethanol volume fractions.

Figure 4 shows the surface tension of different alcohol-water mixtures. N-butanol, n-pentanol, and n-heptanol can greatly reduce the surface tension of the solution, reducing the surface tension of the mixture to below $30 \mathrm{mN} / \mathrm{m}$. The surface tension of the mixed system was almost equal to that of pure alcohol, thereby proving that alcohol is a good agent for reducing surface tension.

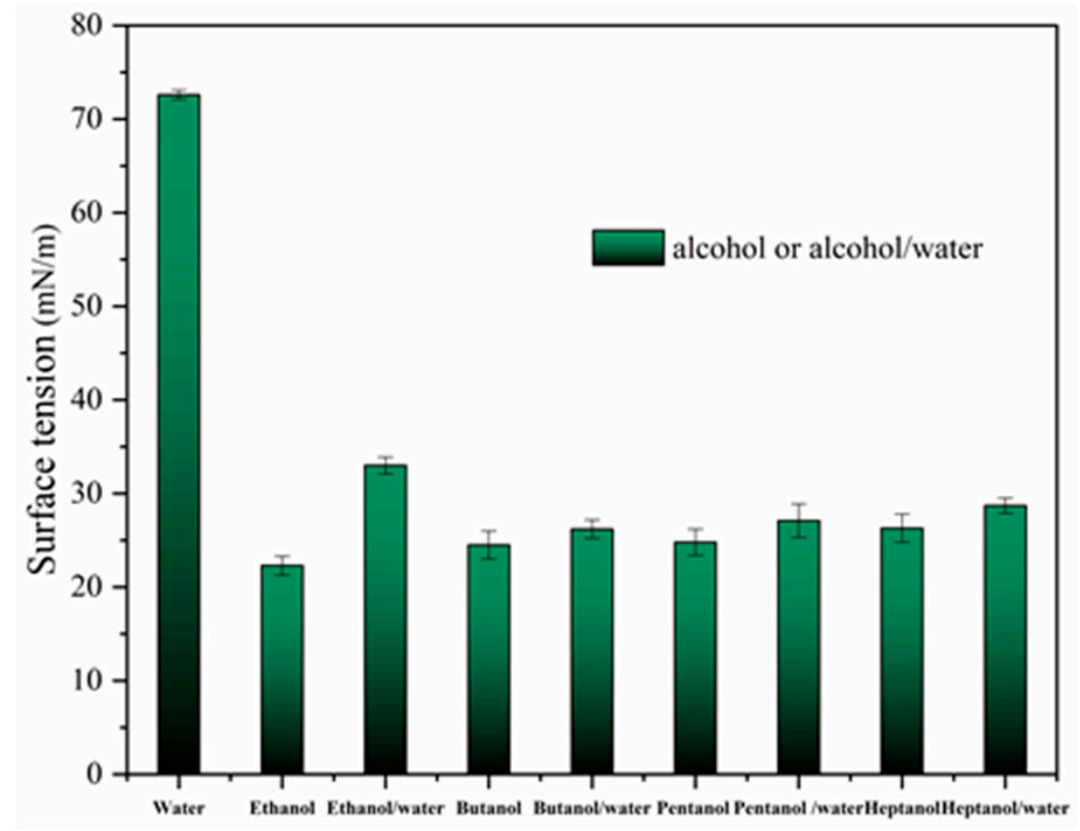

Figure 4. Surface tension of different alcohol-water systems, and the volume fraction of alcohol was 0.2 . 


\subsection{Effect of Alcohol on Azeotrope}

\subsubsection{Azeotropic Temperature of Binary Mixture}

Figure 5a shows the azeotropic temperature between NB and water. Initially, an azeotropic plateau occurred, during which the temperature growth rate was approximately 0 , azeotropic time was approximately $8 \mathrm{~min}$, and the azeotropic temperature was approximately $97.4^{\circ} \mathrm{C}$. As the temperature increased, the balance of the azeotropic ratio between the liquid phase and the gas phase was disturbed, azeotropic plateau period ended, and the temperature gradually increased to the boiling point of water at $100{ }^{\circ} \mathrm{C}$. The short azeotropic time was primarily due to the low NB content, which did not allow the same proportion of gas and liquid mixture for a long time, thereby ending the azeotrope process. Furthermore, previous studies have shown that the organic compound content is only related to the azeotropic time.
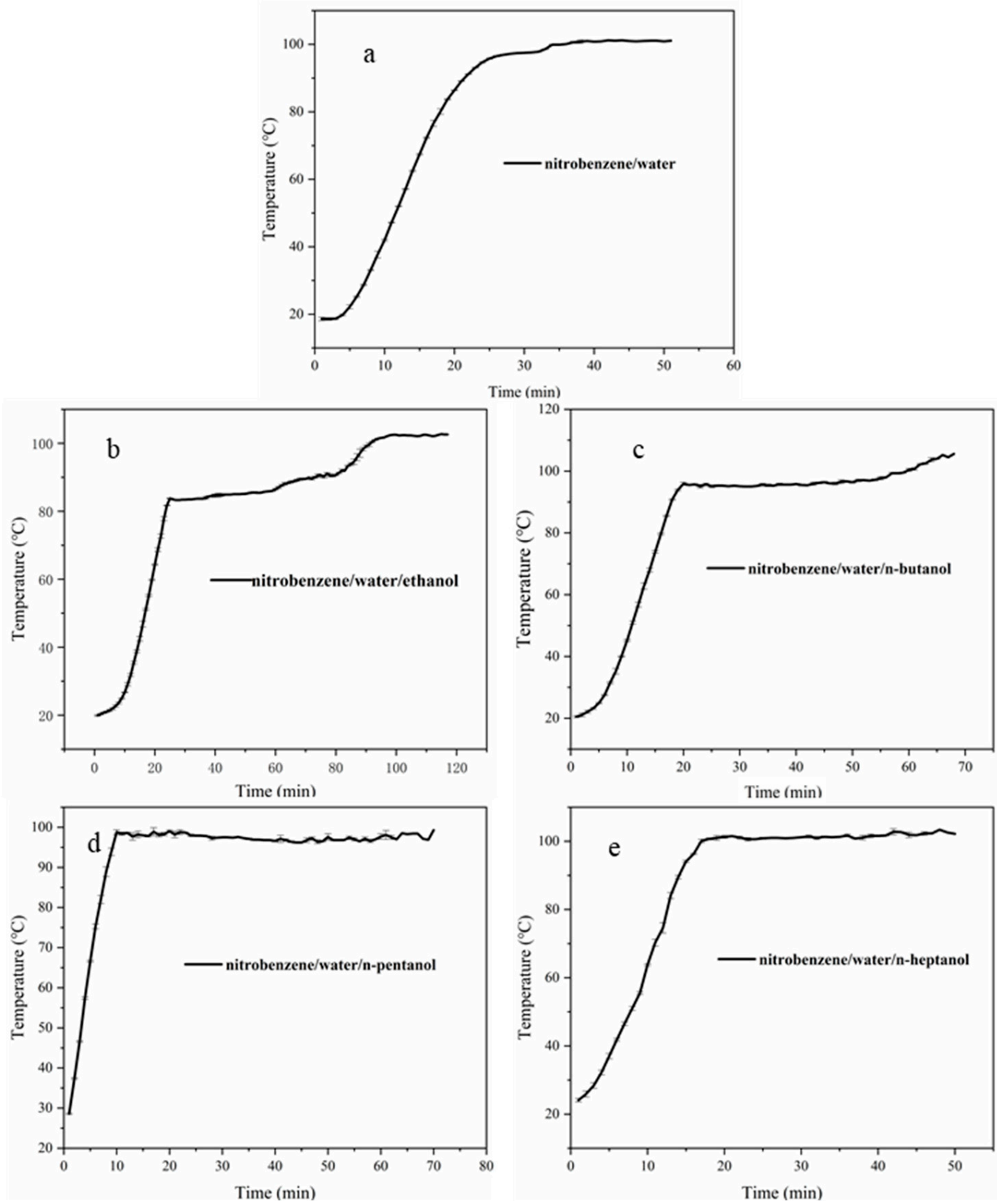

Figure 5. Temperature curves of nitrobenzene (NB)-water (a), NB/water/ethanol (b), NB/water/ n-butanol (c), NB/water/ n-pentanol (d), and NB/water/ n-heptanol (e). 


\subsubsection{Azeotropic Temperature of Ternary Mixture}

The ternary mixture of NB/water/ethanol had an azeotropic plateau (Figure 5b), the azeotropic time lasted for $30 \mathrm{~min}$, azeotropic temperature was $83.2^{\circ} \mathrm{C}$, and temperature increased at $56 \mathrm{~min}$. Compared with the azeotrope of NB and water, adding ethanol could have reduced the azeotrope point by approximately $15^{\circ} \mathrm{C}$, which helped to advance the azeotrope stage by removing NB with hot steam and improving the removal effect. This indicated that ethanol could be used as an azeotropic agent to reduce the azeotropic temperature of NB. The reduction in azeotropic temperature can not only improve the removal efficiency of organic compounds, but also reduce the remediation costs.

The ternary azeotropic mixture of NB, water, and n-butanol entered the azeotropic platform period after $25 \mathrm{~min}$ of recording (Figure $5 \mathrm{c}$ ). The azeotropic temperature was $95.8^{\circ} \mathrm{C}$, and the azeotropic time was $30 \mathrm{~min}$. The azeotropic temperature of the ternary mixture after adding n-butanol was close to that of the binary mixture, which indicated that $n$-butanol was not effective in reducing the azeotropic temperature.

The azeotropic temperature of the NB/water/n-pentanol ternary azeotropic mixture was $97.7^{\circ} \mathrm{C}$ (Figure 5d). N-heptanol was added to the binary mixture of NB/water to form the ternary mixture. The azeotropic temperature was $101.4^{\circ} \mathrm{C}$ (Figure 5e). Compared to the boiling point of water, the addition of $n$-heptanol increased the boiling point of the binary mixture. This indicates that n-pentanol and n-heptanol cannot be used as azeotropic agents to reduce the azeotropic temperature of NB. Only ethanol among the four alcohols could reduce the azeotropic temperature of organic compounds, therefore, ethanol was selected as the enhanced repair reagent in subsequent experiments.

\subsection{Steam Remediation of Heterogeneous Aquifers Contaminated by Nitrobenzene \\ 4.3.1. Temperature Distribution of Layered Heterogeneous Aquifer}

The temperature distribution of the layered heterogeneous aquifer is shown in Figure 6. Due to the high hydraulic conductivity of the lower medium and the low hydraulic conductivity of the upper medium, the upward transmission of steam was inhibited, resulting in heat accumulation below the interface. Therefore, when $\mathrm{R}>1$, a blocking interface is formed, resulting in the formation of steam override below the interface and high temperature in the area below the interface. The higher the $\mathrm{R}$ value, the higher the temperature below the interface, and the greater the lateral migration distance of the steam. The steam in the lower layer primarily relies on heat convection to transfer heat, whereas it primarily relies on heat conduction in the upper low-permeability zone.

\subsubsection{Nitrobenzene Removal in 2-D Layered Heterogeneous Porous Media}

When $\mathrm{R}=17.4$ and steam injection time was $3 \mathrm{~h}$, the NB concentration in the center of the 2-D simulation tank (the position closest to the steam injection point) was the lowest, and the concentration on both sides was high (Figure 7a). This was primarily due to the effect of buoyancy. The vertical migration of steam was faster, resulting in the preferential removal of vertical pollutants. After $6 \mathrm{~h}$ of steam injection, the concentration distribution of NB was affected by the interface, and the concentration was the lowest below the interface, with a concentration of $60 \mathrm{mg} / \mathrm{L}$. After $6 \mathrm{~h}$, the NB removal rate in the simulated tank was $68 \%$, of which the removal rates in gravel and medium sand were $70.3 \%$ and $65.3 \%$, respectively, and the average NB concentration in medium sand was 1.13 times that of gravel.

When $R=381$, the blocking effect of the interface was enhanced (Figure $7 b$ ). The NB concentration in the upper layer was evidently higher than that in the lower layer after $3 \mathrm{~h}$ of steam injection, and the difference was more obvious with the increase in steam injection time. After $6 \mathrm{~h}$ of steam injection, the lowest concentration of NB in gravel reached $28 \mathrm{mg} / \mathrm{L}$, and the average concentration of NB in fine sand was 3.13 times that of gravel. The total removal rate of NB was $60.6 \%$, among which the removal rates in gravel and fine sand were $79.9 \%$ and $37 \%$, respectively. Compared with $R=17.4$, the total removal rate of NB decreased, while the removal rate of NB in gravel increased. 
(a)
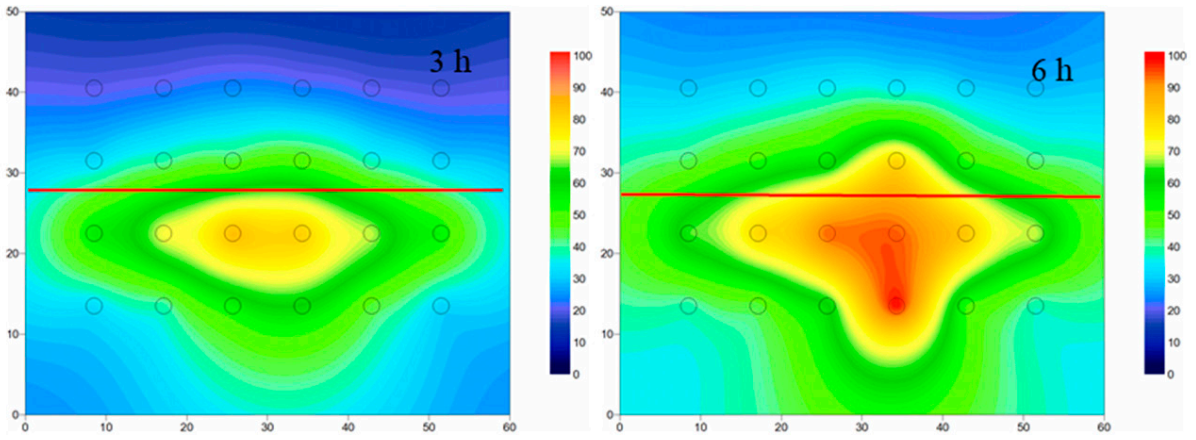

(b)
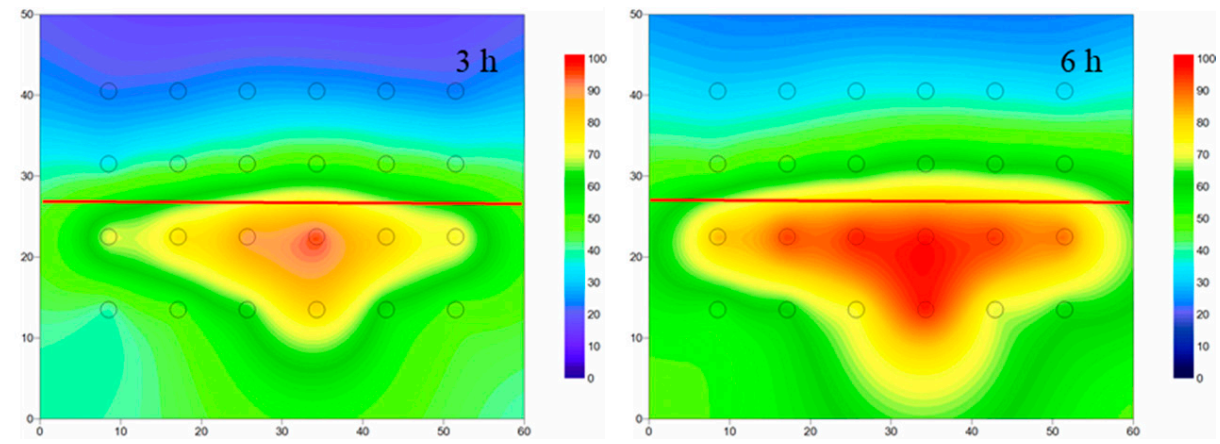

Figure 6. Temperature distribution of the layered heterogeneous aquifers (a) $R=17.4$ (b) $R=381$.

(a)
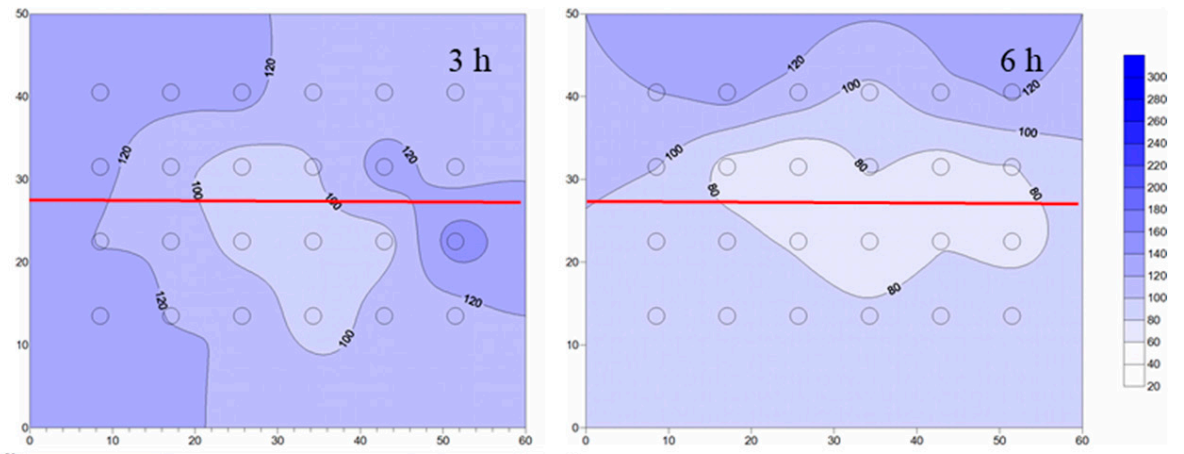

(b)
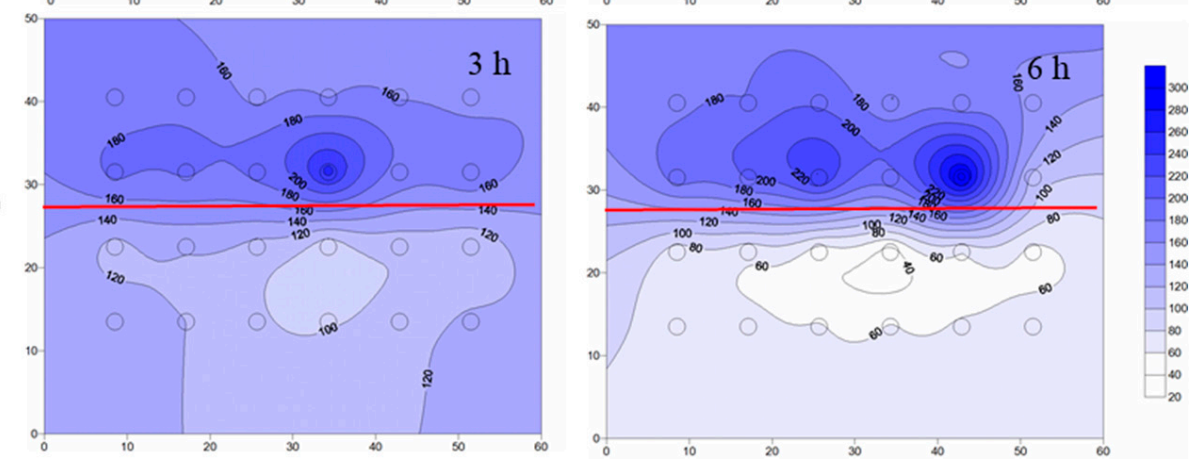

Figure 7. Isograms of $N B$ concentrations with different $R$ values: $(\mathbf{a}) R=17.4 ;(\mathbf{b}) R=381$.

4.3.3. Alcohol-Enhanced Steam Remediation of Layered Heterogeneous Aquifer Contaminated by Nitrobenzene

After adding ethanol, some heat was accumulated at the interface, but the temperature difference between the upper and lower layers decreased significantly, the average temperature increased by $15{ }^{\circ} \mathrm{C}$, and the area affected by steam in the low-permeability zone increased by $35 \%$ (Figure 8). Alexeev et al. (2005) found that Marangoni convection could enhance liquid phase heat transfer through experimental and numerical simulation [41]. 
Therefore, the addition of ethanol produces Marangoni convection and enhances mass and heat transfer.

(a)
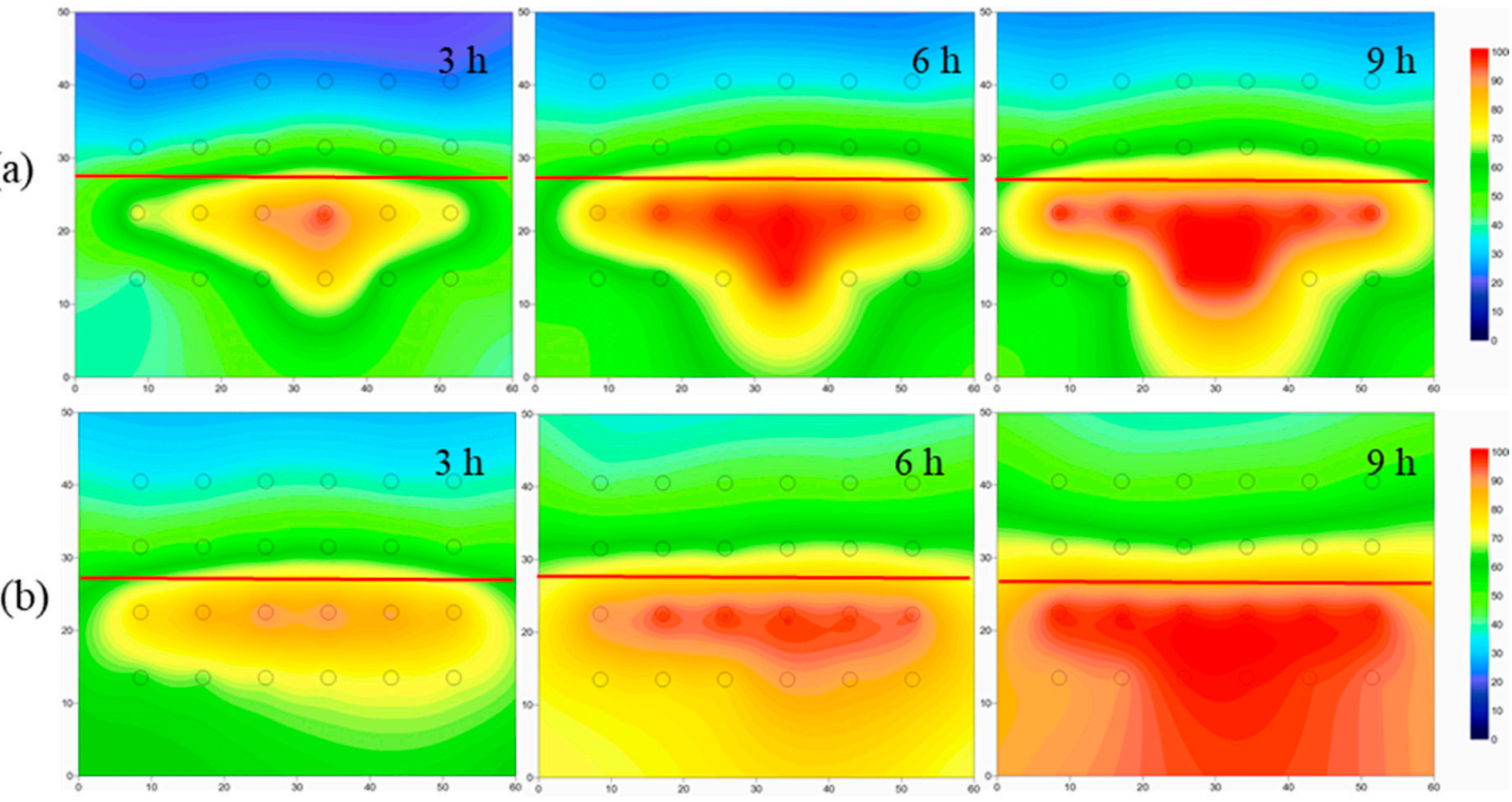

Figure 8. Temperature distribution without ethanol (a) and with ethanol (b) at $\mathrm{R}=381$.

After adding ethanol, the remediation effect of NB was significantly increased, particularly in the fine sand medium (Figure 9) and the average NB concentration in the simulated tank was reduced by $51 \%$. The average concentration of NB in the lower gravel and upper fine sand decreased by $43.7 \%$ and $43.5 \%$, respectively, indicating that ethanol addition enhanced the gas-liquid mass transfer. During the repair process, ethanol volatilized at the gas-liquid interface, forming a surface tension gradient at the interface and increasing the convective vortices in the flow field, resulting in the Marangoni convection [20,40,42]. The Marangoni convection can also enhance heat transfer, and an increase in temperature also enhances NB removal. In addition, ethanol reduces the azeotropic temperature of NB, promoting the boiling of $\mathrm{NB}$ at $83.2^{\circ} \mathrm{C}$, thus, improving the removal rate and efficiency of NB.

4.3.4. Alcohol-Enhanced Steam Remediation of Lens Heterogeneous Aquifer Contaminated with NB

Figure 10 shows the temperature distribution of the aquifers containing lenses with and without ethanol solution. Due to the existence of a low-permeability lens, a blocking interface was formed below the lens, and steam flowed around the lens. Only a small amount of steam could enter the fine-sand lens, causing the temperature inside the lens to increase. However, most steam will flow around the lens from the high-permeability area in the form of preferential flow, resulting in an uneven distribution of steam, which affects the removal effect of NB. After adding ethanol, the average temperature in the simulated tank increased by $8{ }^{\circ} \mathrm{C}$, and the steam-affected area increased by $14 \%$, which further confirms that the Marangoni convection generated by ethanol can enhance heat and mass transfer. 

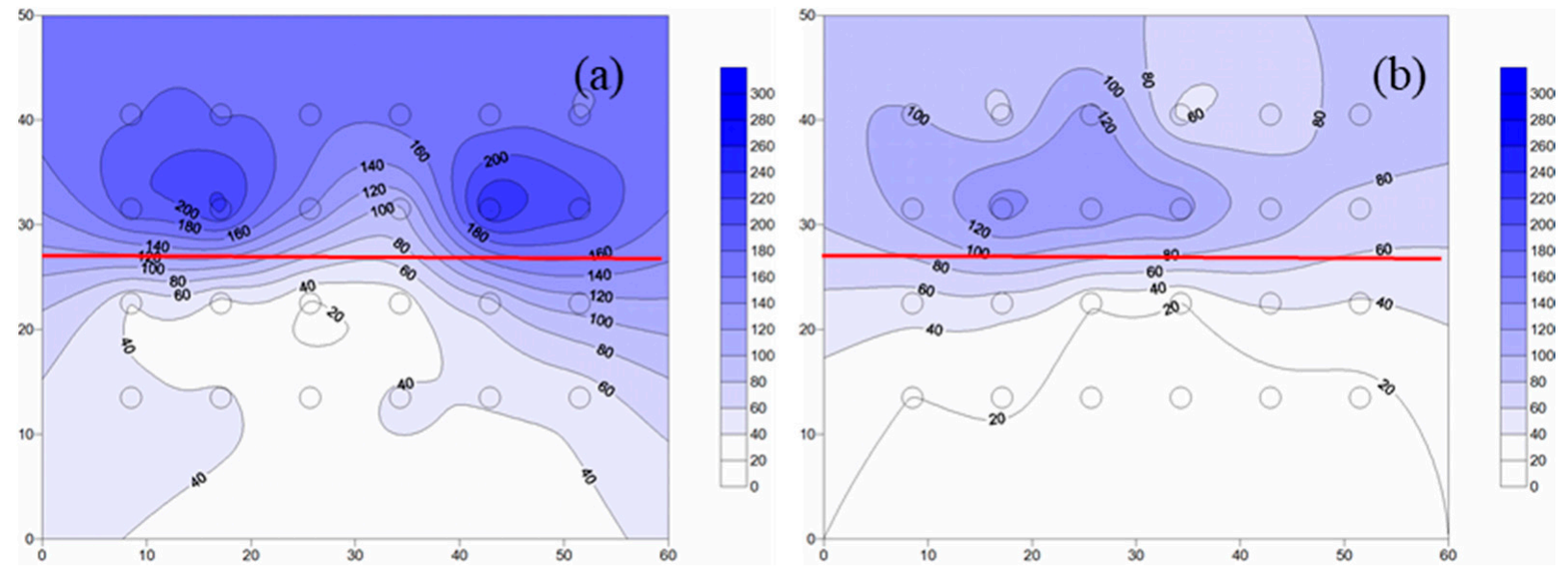

Figure 9. Isograms of NB concentration without ethanol (a) and with ethanol (b) at $9 \mathrm{~h}$.

(a)
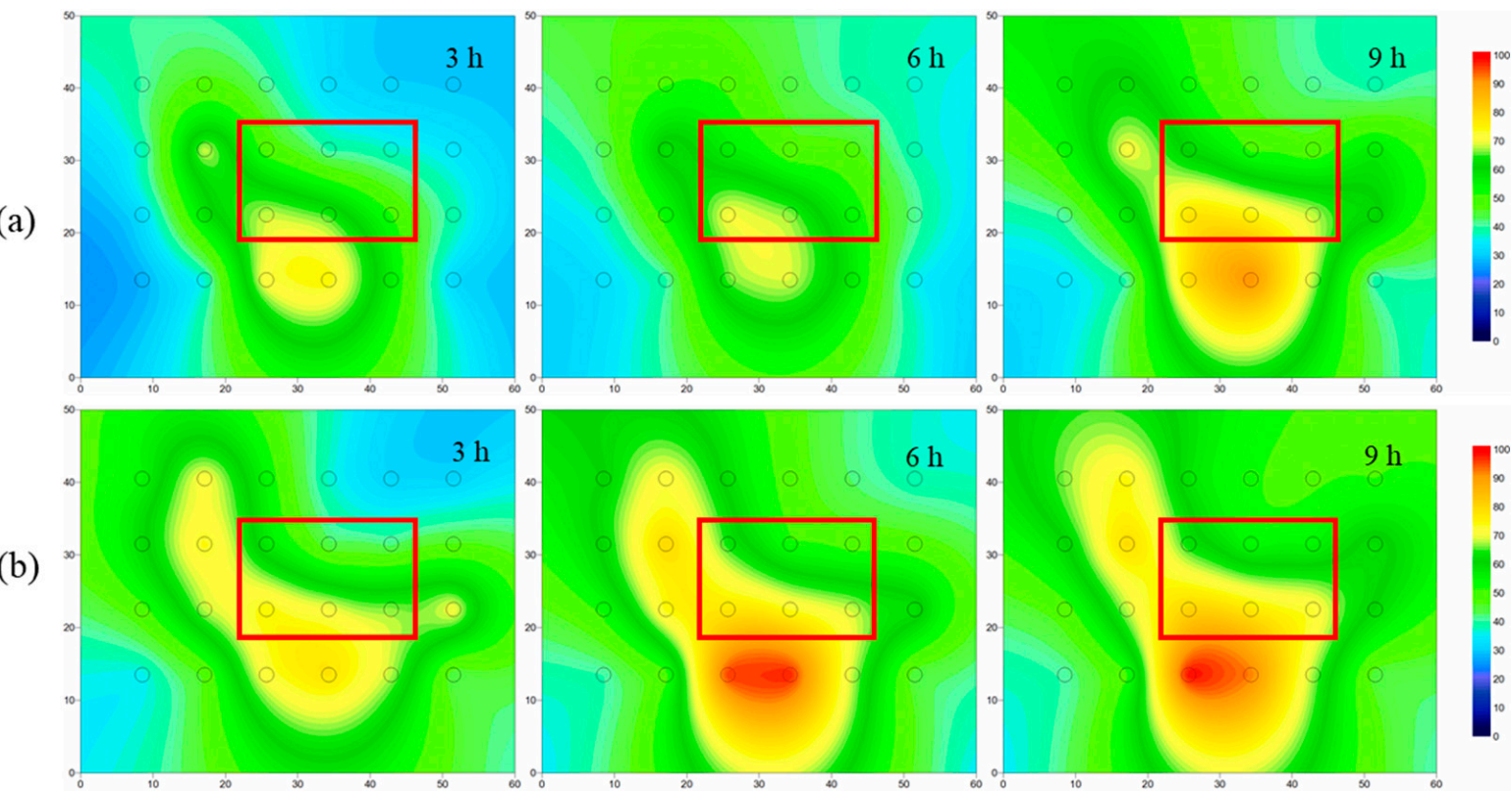

Figure 10. Temperature distribution without ethanol (a) and with ethanol (b) in the lens heterogeneous aquifer.

Figure 11 shows the isolines of NB concentration in the heterogeneous aquifer with the lens. In the lens heterogeneous aquifer, the remediation effect of steam at the edge of the simulation tank and in the lens was weakened due to the preferential flow. After ethanol was added, the mass transfer and heat transfer were enhanced, and the boiling area increased, resulting in an increase in the removal efficiency of NB. The removal efficiency of the tank was increased by $10 \%$, and the NB concentration in the lens was reduced by approximately $58 \%$. Under the same steam flow rate, ethanol addition enhanced the remediation effect of the lens heterogeneous aquifer and reduced the remediation time and cost. 
(a)
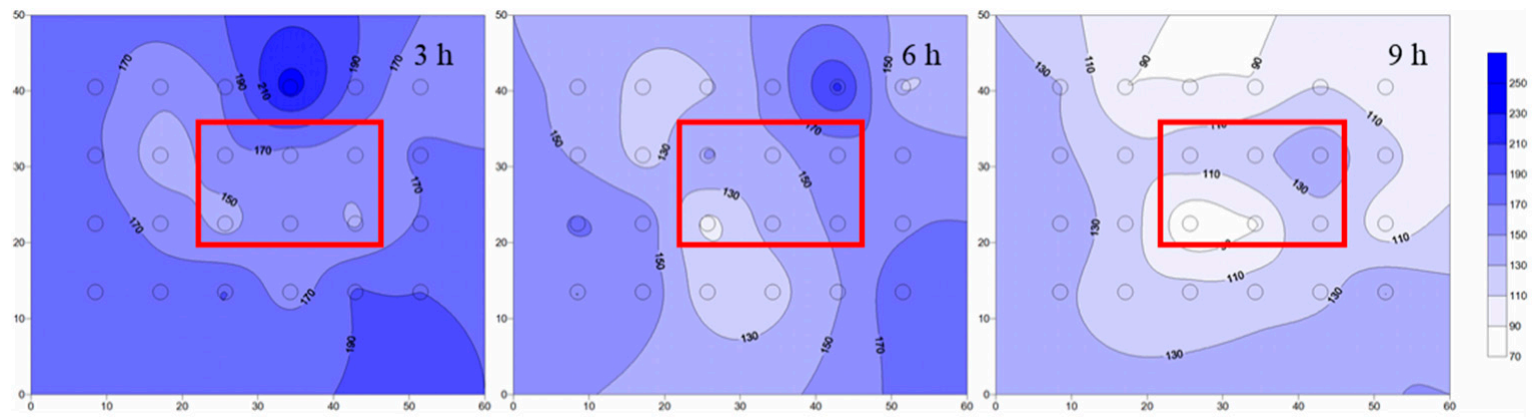

(b)
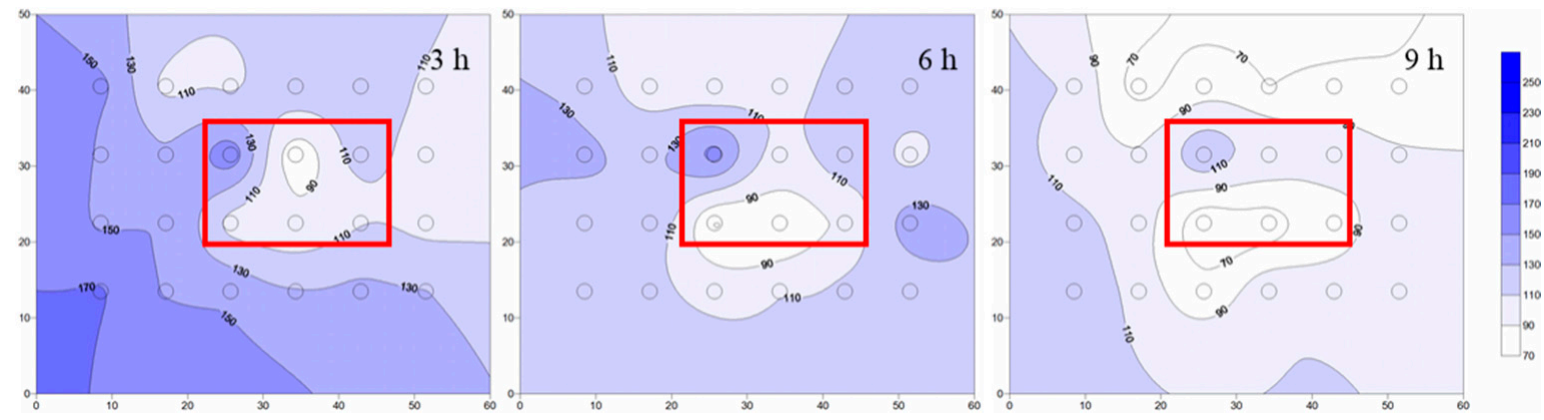

Figure 11. Isograms of NB concentration without ethanol (a) and with ethanol (b) in the heterogeneous aquifer.

\section{Conclusions}

(1) The four alcohols reduced the surface tension of the solution from $72 \mathrm{mN} / \mathrm{m}$ to less than $30 \mathrm{mN} / \mathrm{m}$; however, among the four alcohols, only ethanol reduced the azeotropic temperature of NB by $15{ }^{\circ} \mathrm{C}$. Therefore, ethanol can be used as a remediation agent to enhance the steam remediation of heterogeneous aquifers.

(2) When steam entered the layered heterogeneous aquifer, the interface between the low-and high-permeability strata blocked the steam transmission, resulting in poor remediation effect of the low-permeability stratum. After adding ethanol, the average temperature increased, and the area affected by steam increased by $13 \%$, which proved that ethanol addition increased the steam transmission. Moreover, the removal effect of NB was significantly improved, and the average concentration of NB in the simulation tank decreased by $51 \%$.

(3) In the lens heterogeneous aquifer, steam flowed around the lens, forming a preferential flow that resulted in the reduced removal of NB from the lens. After adding ethanol, the steam-affected area increased by $14 \%$, the removal rate of NB increased by $10 \%$, and the NB concentration in the lens decreased by $58 \%$.

(4) Ethanol-enhanced steam injection remediation of heterogeneous aquifers not only enhances the remediation effect and increases the remediation range, but also reduces the remediation costs.

Author Contributions: R.L.: Conceptualization, Investigation, Formal analysis, Writing-original draft. X.Y.: Investigation, Validation. J.X.: Investigation, Validation. X.L.: Investigation, Validation. Y.Z.: Conceptualization, Resources, Writing-review \& editing. All authors have read and agreed to the published version of the manuscript.

Funding: This work was supported by the National Nature Science Foundation of China (Grant No. 41530636), the National and Local Joint Engineering Laboratory for Petrochemical Contaminated Site Control and Remediation Technology of Jilin University, the Jilin Provincial Key Laboratory of Water Resources and Environment of Jilin University, and the Key Laboratory of Groundwater Resources and Environment of Ministry of Education (Jilin University).

Institutional Review Board Statement: Not applicable.

Informed Consent Statement: Not applicable. 
Data Availability Statement: Some or all data, models, or codes that support the findings of this study are available from the corresponding authors on request.

Acknowledgments: This study was financially supported by the Key Project of the National Natural Science Foundation of China (Grant No. 41530636). The authors thank the Key Laboratory of Groundwater Resources and Environment, Ministry of Education for providing financial assistance.

Conflicts of Interest: The authors declare no conflict of interest.

\section{References}

1. Al Yousef, Z.; AlDaif, H.; Al Otaibi, M. An overview of steam injection project in Fractured Carbonate Reservoirs in the Middle East. J. Pet. Sci. Res. 2014, 3, 101-110. [CrossRef]

2. Davis, E.L. Steam injection for soil and aquifer remediation. Environ. Prot. Agency 1998, 505, 1-16.

3. Udell, K.S. Application of in situ thermal remediation technologies for DNAPL removal. Groundw. Qual. Remediat. Prot. 1998, 250, 367-374.

4. Gudbjerg, J.; Sonnenborg, T.O.; Jensen, K.H. Remediation of NAPL below the water table by steam-induced heat conduction. J. Contam. Hydrol. 2004, 72, 207-225. [CrossRef]

5. Basel, M.D.; Udell, K.S. Effect of Heterogeneities on the Shape of Condensation Fronts in Porous Media; American Society of Mechanical Engineers: New York, NY, USA, 1991; pp. 63-70.

6. Schmidt, R.; Gudbjerg, J.; Sonnenborg, T.O.; Jensen, K.H. Removal of NAPLs from the unsaturated zone using steam Prevention. J. Contam. Hydrol. 2002, 55, 233-260. [CrossRef]

7. Heron, G.; Christensen, T.H.; Enfield, C.G. Henry's law constant for trichloroethylene between 10 and $95^{\circ} \mathrm{C}$. Environ. Sci. Technol. 1998, 32, 1433-1437. [CrossRef]

8. Schwardt, A.; Dahmke, A.; Köber, R. Henry's law constants of volatile organic compounds between 0 and $95^{\circ} \mathrm{C}-\mathrm{Data}$ compilation and complementation in context of urban temperature increases of the subsurface. Chemosphere 2021, 272, 129858. [CrossRef]

9. Sleep, B.E.; McClure, P.D. The effect of temperature on adsorption of organic compounds to soils. Can. Geotech. J. 2001, 38, 46-52. [CrossRef]

10. Philippe, N.; Davarzani, H.; Colombano, S.; Dierick, M.; Klein, P.-Y.; Marcoux, M. Experimental study of the temperature effect on two-phase flow properties in highly permeable porous media: Application to the remediation of dense non-aqueous phase liquids (DNAPLs) in polluted soil. Adv. Water Resour. 2020, 146, 103783. [CrossRef]

11. Tzovolou, D.N.; Aggelopoulos, C.A.; Theodoropoulou, M.A.; Tsakiroglou, C.D. Remediation of the unsaturated zone of NAPLpolluted low permeability soils with steam injection: An experimental study. J. Soils Sediments 2010, 11, 72-81. [CrossRef]

12. Heron, G.; Vanzutphen, M.; Christensen, H.T.; Enfield, G.C. Soil heating for enhanced remediation of chlorinated solvents_a laboratory study on resistive heating and vapor extraction in a silty, low-permeable soil contaminated with trichloroethylene. Environ. Sci. Technol. 1998, 32, 1474-1481. [CrossRef]

13. Ochs, S.O.; Class, H.; Färber, A.; Helmig, R. Methods for predicting the spreading of steam below the water table during subsurface remediation. Water Resour. Res. 2010, 46, 1-16. [CrossRef]

14. Class, H.; Helmig, R. Numerical simulation of non-isothermal multiphase multicomponent processes in porous media. 2. Applications for the injection of steam and air. Adv. Water Resour. 2002, 25, 551-564. [CrossRef]

15. Nilsson, B.; Tzovolou, D.; Jeczalik, M.; Kasela, T.; Slack, W.; Klint, K.E.; Haeseler, F.; Tsakiroglou, C.D. Combining steam injection with hydraulic fracturing for the in situ remediation of the unsaturated zone of a fractured soil polluted by jet fuel. J. Environ. Manage. 2011, 92, 695-707. [CrossRef] [PubMed]

16. Davis, E.; Akladiss, N.; Hoey, R.; Brandon, B.; Nalipinski, M.; Carroll, S.; Herom, G.; Novakowski, K.; Udell, K. Steam Enhanced Remediation Research for DNAPL in Fractured Rock. EPA 2005, 10, 1-190.

17. Baker, R.S.; Heron, G. In-Situ Delivery of Heat by Thermal Conduction and Steam Injection for Improved Dnapl Remediation. In Proceedings of the 4th International Conference on Remediation of Chlorinated and Recalcitrant Compounds, Monterey, CA, USA, 24-27 May 2004; Battelle Press: Monterey, CA, USA, 2004.

18. Heron, G.; Carroll, S.; Nielsen, S.G. Full-Scale Removal of DNAPL Constituents Using Steam-Enhanced Extraction and Electrical Resistance Heating. Ground Water Monit. Remediat. 2005, 25, 92-107. [CrossRef]

19. Chao, H.P.; Hsieh, L.C.; Tran, H.N. Increase in volatilization of organic compounds using air sparging through addition in alcohol in a soil-water system. J. Hazard. Mater. 2018, 344, 942-949. [CrossRef]

20. Chang, Y.; Yao, M.; Bai, J.; Zhao, Y. Study on the effects of alcohol-enhanced air sparging remediation in a benzene-contaminated aquifer: A new insight. Environ. Sci. Pollut. Res. Int. 2019, 26, 35140-35150. [CrossRef]

21. Abd Rahman, N.; Azizan, N.A.; Kamaruddin, S.A.; Chelliapan, S.; Mohd Jaini, Z.; Yunus, R.; Rahmat, S.N. Steam-Enhanced Extraction Experiments, Simulations and Field Studies for Dense Non-Aqueous Phase Liquid Removal: A Review. MATEC Web Conf. 2016, 47, 05012. [CrossRef]

22. Yuan, Z.; Herold, K.E. Surface tension of pure water and aqueous lithium bromide with 2-ethyl-hexanol. Appl. Therm. Eng. 2001, 21, 881-897. [CrossRef]

23. Biscay, F.; Ghoufi, A.; Malfreyt, P. Surface tension of water-alcohol mixtures from Monte Carlo simulations. J. Chem. Phys. 2011, 134, 044709. [CrossRef] 
24. Moraveji, M.K.; Sajjadi, B.; Davarnejad, R. Gas-Liquid Hydrodynamics and Mass Transfer in Aqueous Alcohol Solutions in a Split-Cylinder Airlift Reactor. Chem. Eng. Technol. 2011, 34, 465-474. [CrossRef]

25. Chen, F.; Freedman, D.L.; Falta, R.W.; Murdoch, L.C. Henry's law constants of chlorinated solvents at elevated temperatures. Chemosphere 2012, 86, 156-165. [CrossRef] [PubMed]

26. Koproch, N.; Dahmke, A.; Kober, R. The aqueous solubility of common organic groundwater contaminants as a function of temperature between 5 and $70{ }^{\circ} \mathrm{C}$. Chemosphere 2019, 217, 166-175. [CrossRef]

27. Komninos, N.P.; Rogdakis, E.D. Geometrical investigation and classification of three-suffix margules binary mixtures including single and double azeotropy. Fluid Phase Equilib. 2019, 494, 212-227. [CrossRef]

28. Maalem, Y.; Zarfa, A.; Tamene, Y.; Fedali, S.; Madani, H. Prediction of thermodynamic properties of the ternary azeotropic mixtures. Fluid Phase Equilib. 2020, 517, 112613. [CrossRef]

29. Imaishi, N.; Suzuki, Y.; Hozawa, M.; Fujinawa, K. Interfacial turbulence in gas-liquid mass transfer. Int. Chem. Eng. 1982, 22, 659-665. [CrossRef]

30. Marangoni, C. Ueber die Ausbreitung der Tropfen einer Flüssigkeit auf der Oberfläche einer anderen. Ann. Der Phys. Und Chem. 1871, 219, 337-354. [CrossRef]

31. Bénard, H. Les Tourbillons Cellulaires_Dans une Nappe Liquide Propageant de la Chaleur par Convection, en Régime Permanent; Thèse Présentée à la Faculté des Sciences de Paris; Par, M., Bénard, H., Eds.; Gauthier-Villars: Paris, France, 1901.

32. Rayleigh, L. LIX. On convection currents in a horizontal layer of fluid, when the higher temperature is on the under side. Lond. Edinb. Dublin Philos. Mag. J. Sci. 1916, 32, 529-546. [CrossRef]

33. Mao, Z.-S.; Chen, J. Numerical simulation of the Marangoni effect on mass transfer to single slowly moving drops in the liquid-liquid system. Chem. Eng. Sci. 2004, 59, 1815-1828. [CrossRef]

34. Ma, Y.; Yu, G.; Li, H.Z. Note on the mechanism of interfacial mass transfer of absorption processes. Int. J. Heat Mass Transf. 2005, 48, 3454-3460. [CrossRef]

35. Bodenschatz, E.; de Bruyn, J.R.; Ahlers, G.; Cannell, D.S. Transitions between patterns in thermal convection. Phys. Rev. Lett. 1991, 67, 3078-3081. [CrossRef]

36. Vidal, A.; Acrivos, A. Effect of Nonlinear Temperature Profiles on Onset of Convection Driven by Surface Tension Gradients. Ind. Eng. Chem. Fundam. 1968, 7, 53-58. [CrossRef]

37. McTaggart, C.L. Convection driven by concentration- and temperature-dependent surface tension. J. Fluid Mech. 1983, 134, 301-310. [CrossRef]

38. Buffone, C.; Sefiane, K.; Easson, W. Marangoni-driven instabilities of an evaporating liquid-vapor interface. Phys. Rev. E 2005, 71, 056302. [CrossRef]

39. Sha, Y.; Chen, H.; Yin, Y.; Tu, S.; Ye, L.; Zheng, Y. Characteristics of the Marangoni Convection Induced in Initial Quiescent Water. Ind. Eng. Chem. Res. 2010, 49, 8770-8777. [CrossRef]

40. Liu, D.; Tran, T. Vapor-Induced Attraction of Floating Droplets. J. Phys. Chem. Lett. 2018, 9, 4771-4775. [CrossRef] [PubMed]

41. Alexeev, A.; Gambaryan-Roisman, T.; Stephan, P. Marangoni convection and heat transfer in thin liquid films on heated walls with topography: Experiments and numerical study. Phys. Fluids 2005, 17, 062106. [CrossRef]

42. Zhang, J.; Oron, A.; Behringer, R.P. Novel pattern forming states for Marangoni convection in volatile binary liquids. Phys. Fluids 2011, 23, 072102. [CrossRef] 